\title{
Remote Sensing and GIS Approach for Landslide Susceptibility Mapping: A Case Study in Hofu City, Yamaguchi, Japan
}

\author{
Benita Nathania a,b*, Fusanori Muira b \\ ${ }^{a}$ Center for Remote Sensing and Ocean Science (CReSOS), Udayana University, PB Sudirman Street, Post \\ Graduate Building, Denpasar, Bali 80232, Indonesia \\ ${ }^{b}$ Disaster Prevention System Laboratory, Environmental Science and Engineering Division, Graduate School of \\ Sciences and Technology for Innovation, Yamaguchi University, 2-16-1 Tokiwadai, Ube, Yamaguchi 755-8611, \\ Japan
}

* Correspondence: benithania@yahoo.com

Received: 12 July 2016; Accepted: 25 February 2017; Available online: 27 February 2017

\begin{abstract}
Landslide is one of the natural hazards that often initiates by the interaction between environmental factors and triggering factor. The identification of areas where landslides are likely to occur is important for the reduction of potential damage. This study utilizes remote sensing data and Geographic Information System (GIS) to identify areas where landslides are likely to occur and generates landslide susceptibility map based on logistic regression model. The study area is located in Hofu city, Yamaguchi prefecture, Japan. The data that were used in this study are satellite imagery from ALOS AVNIR-2, elevation and geology data from GSI, Rainfall data from AMEDAS, and landslide inventory map provided from Ministry of Land, Infrastructure, Transportation and Tourism. The result from this study revealed that elevation from $>50$ to $<350 \mathrm{~m}$, slope angle from $>$ $5^{\circ}$ to $<50^{\circ}$, slope direction of north and northeast, land cover of agriculture, urban, bare soil, and forest, and lithology of graniodorite, fan deposits, and middle terrace are favorable for landslide occurrence. The landslide susceptiility map showed that $98 \%$ of the result calculations of logistic regression are similar to the historical data of landslide event which is among 911 landslide points, 899 points were existed in high and very high susceptibility areas.
\end{abstract}

Keywords: landslide; satellite imagery; geographical information system (GIS); susceptibility mapping

\section{Introduction}

Landslide is one of the natural disasters that occur frequently and evenly spread in almost all parts of Japan. Since only 25\% of Japan's land area is flat and low lying with plateaus, the Japanese people have suffered numerous landslide disasters since ancient times (The Japan Landslide Society, 1994). Landslides generally occur along gently to moderately sloping grounds which are also important as these areas include residential and agricultural use. The interaction between environmental factors and triggering factor often initiates the landslide occurrence. In Japan, the common triggering factors are high rainfall intensity and earthquake. A report from Road bureau of Ministry of land, Infrastructure, Transport and Tourism (MLIT) of Japan government revealed that from year 1990 to 2004 more than $90 \%$ of landslide disasters were caused by rainfall and only $2 \%$ by earthquake.

The identification of areas where landslides are likely to occur is important for the reduction of potential damage, but to obtain information of landslide data through field survey methods in mountainous area is quite difficult, time consuming, and relatively expensive. Remote sensing technology provides more effective way to obtain data in poor accessible areas. Remote sensing also provides a biophysical data that has a contribution to the occurrence of landslides such as land cover and digital elevation model (DEM). 
Integration of remote sensing technology and Geographic Information System (GIS) as an instrument of spatial analysis is useful way to provide more efficient and effective way to observe landslide event. The logistic regression model is one of probabilistic model that evaluated landslide susceptibility by using Geographic Information System (GIS). The logistic regression model has been widely used to establish the relationship between landslide and causative factors and landslide occurrence.

The objectives of this study are: 1) to identify areas where landslides are likely to occur using remote sensing and GIS approach; 2) to generate landslide susceptibility map using logistic regression model.

\section{Materials and Methods}

\subsection{Research Study Area}

This research was carried out in Hofu City, Yamaguchi Prefecture, as shown in Figure 1. The total area of Hofu city is $188.59 \mathrm{~km}^{2}$. An extra-ordinary intense rainstorm which caused by stationary front (Baiu front) was recorded in Hofu City of Yamaguchi Prefecture in 21 July 2009, which occur once in a period of 200-600 years statistically. It induced many debris flow disaster and claiming 14 residents live.

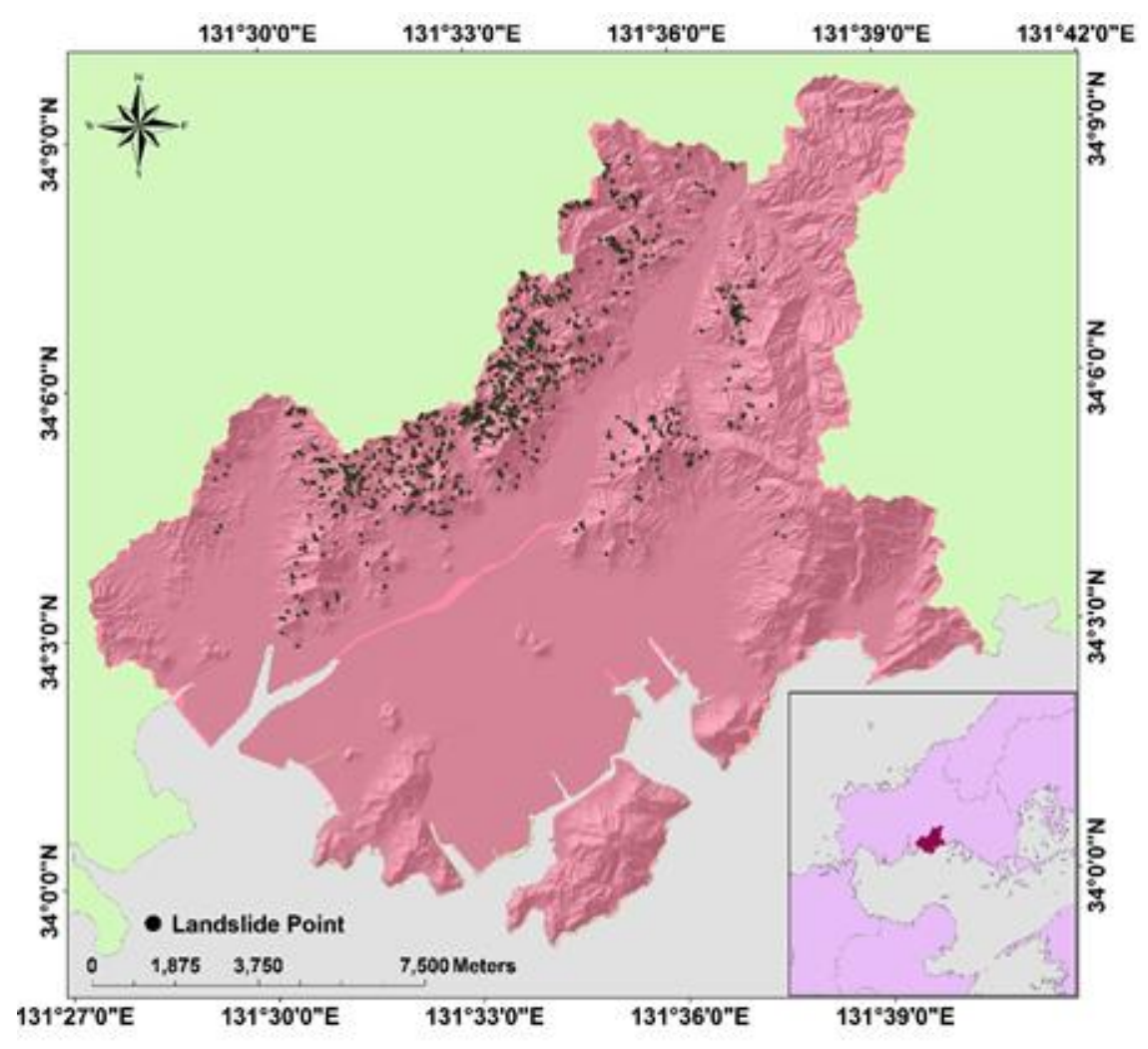

Figure 1. Hofu City and its landslide inventory map

\subsection{Data Collection}

The data used in this research are as follows:

1. Landslide inventory map was collected by Ministry of Land, Infrastructure, Transportand Tourism, Chugoku District, Japan.

2. ALOS AVNIR-2 image with the time acquisition of 14 July 2009 was processed by using ENVI 4.8 software, was used to create land cover map.

3. Rainfall data was downloaded from AMEDAS (Automated Meteorological Data Acquisition System) website http://www.jma.go.jp/jma/index.html.

4. Geology and elevation data was obtained from The Geospatial Information Authority of Japan (GSI) website http://www.gsi.go.jp. 


\subsection{Data Analysis}

\subsubsection{ALOS AVNIR-2 Processing}

Remote sensing satellite detectors exhibit linear response to incoming radiance, whether from the Earth's surface radiance or internal calibration sources. This response is quantized into 8-bit values that represent brightness values commonly called Digital Numbers (DN). To convert the calibrated digital numbers to at-aperture radiance, rescaling gains and biases are created from the known dynamic range limits of the instrument. Equation (1) describes the algorithm for DN to radiance conversion (Bouvet et al., 2007).

in which $L_{\lambda}$ is the spectral radiance at the sensor's aperture $\left(\mathrm{W} / \mathrm{m}^{2} / \mathrm{sr} / \mu \mathrm{m}\right)$, Grescale is the rescaled gain, QCAL is the DN, and Brescale is the rescaled bias. For relatively "clear" scenes, a reduction in between-scene variability can be achieved through normalization for solar irradiance by converting the spectral radiance to a planetary or exoatmospheric reflectance. Equation (2) describes the algorithm for radiance to reflectance conversion (Sah et al., 2012).

\subsubsection{Land Cover Classification}

Object-based image analysis (OBIA) is a method of image analysis that uses objects in a scene rather than individual pixels to derive information from the imagery. OBIA is a two-part process consisting of image segmentation and then image classification. After the segmentation process finished the image then classified using the K Nearest Neighbour classification method.

\subsubsection{Isohyet}

Isohyet is a line drawn on a weather map connecting points that receive equal amounts of precipitation during a given period of time. An isohyet map is a map that displays precipitation data. The contoured lines connect areas of equal rainfall, and many times a color scale is used to differentiate between areas. Isohyet maps are prepared by interpolating rainfall data recorded at gauged points (Chow et al., 1988).

\subsubsection{Digital Elevation Model}

A digital elevation model (DEM) consists of terrain elevations for ground positions at regularly spaced horizontal intervals. The original elevation point derived from GSI was converted into raster DEM through Inverse Distance Weighted (IDW) interpolation. IDW interpolation determines cell values using a linearly weighted combination of a set of sample points. The weight is a function of inverse distance. The surface being interpolated should be that of a locationally dependent variable. DEMs are used in the generation of slope and aspect.

\subsubsection{Weights of Evidence and Logistic Regression Model}

Weights of Evidence (WOE) is a quantitative statistical approach based on the Bayesian probability model, where conditional probability is based on evidence (Bonham-Carter and Cox, 1995). Positive and negative weights, denoted as $\mathrm{W}+$ and $\mathrm{W}-$ respectively defined by equations (3) and (4), express the importance of parameter classes. A positive $\mathrm{W}+$ indicates that the parameter class is favourable for the occurrence of landslides. A negative $\mathrm{W}-$ means that the absence of the class reduces the landslide susceptibility. The calculation of weights is based on an area cross-tabulation of landslide area and the parameter class, as shown in Table 1 (Bonham-Carter and Cox, 1995) as follows: 
Table 1. Area croos-tabulation

\begin{tabular}{lccc}
\hline \multirow{2}{*}{ Landslide Area } & \multicolumn{3}{c}{ Parameter Class } \\
& Present & Absence & Total \\
\hline Present & $\mathrm{T}_{11}$ & $\mathrm{~T}_{12}$ & $\mathrm{~T}_{1}$ \\
Absence & $\mathrm{T}_{21}$ & $\mathrm{~T}_{22}$ & $\mathrm{~T}_{2}$ \\
Total & $\mathrm{T}_{.1}$ & $\mathrm{~T}_{2}$ & $\mathrm{~T} .$. \\
\hline
\end{tabular}

Logistic regression (LR) is a multivariate statistical technique appropriate for estimating the probability of a dichotomous dependent variable, such as the occurrence or absence of landslides, from its relations with independent variables, like slope gradient, lithology, land cover, etc. The result is probability values between 0 and 1 . The probability values can be assimilated as landslide susceptibility.

LR has been applied to mineral potential prediction (Agterberg et al., 1993) and landslide susceptibility assessment (Ayalew et al., 2005; Brenning, 2005; Dai and Lee, 2002; Robinson and Larkins, 2007). Advantages of LR are that it can be applied when the variables show conditional dependence and it can be used when variables have many classes or are continuous. LR is based on the logistic function, $\mathrm{f}(\mathrm{z})$ :

Where

(6)

LR consists in the calculation of constant or intercept, $a_{0}$, and the coefficients $\beta_{1}, \beta_{2}, \ldots \beta_{k}$. Variables $\mathrm{X}_{1}, \mathrm{X}_{2}, \mathrm{X}_{\mathrm{k}}$, correspond to the independent variables, or landslide related factors here.

\section{Results and Discussion}

Early summer stationary rain front (Baiu Front) caused a heavy rainstorm in Hofu city in the study area on 21 July 2009. The highest total rainfall recorded on that day was 274 $\mathrm{mm}$. This rainfall caused a large number of shallow landslides in the mountain slopes around Hofu area and considered as the triggering factor. Figure 2 (a) shows the rainfall distribution map in July 2009, while (b) shows the daily rainfall rate in July 2009.

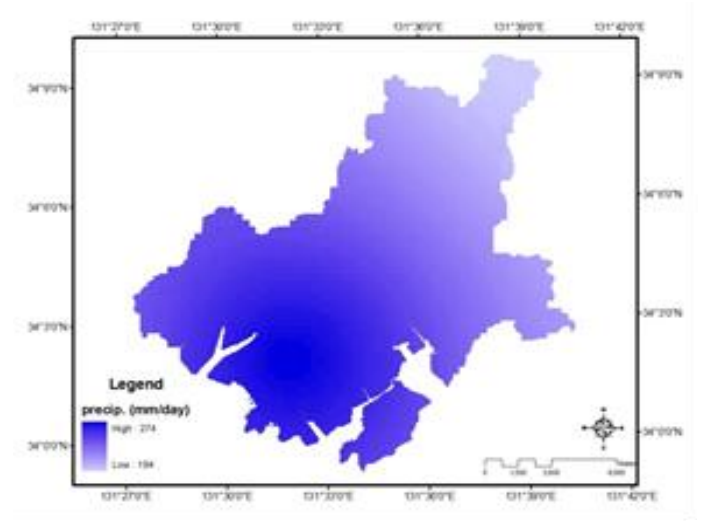

(a)

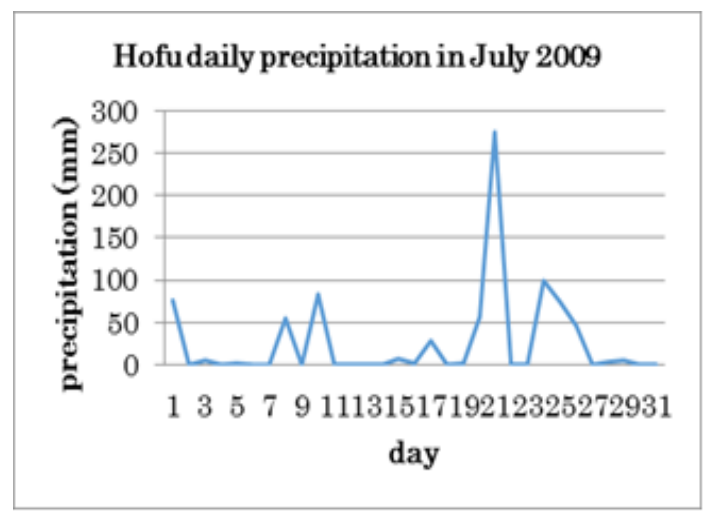

(b)

Figure 2. Rainfall map and daily precipitation rate. 
Landslide susceptibility map was obtained by logistic regression model and using five parameters including elevation, slope, aspect, land cover, and lithology. Weight of evidence was used to examine the spatial association between the training sites and each evidence map of interest. Weight calculation was executed using Arc-SDM tool. Landslide parameters map and its weight are shown in Fig. 3, 4, 5, 6, 7.

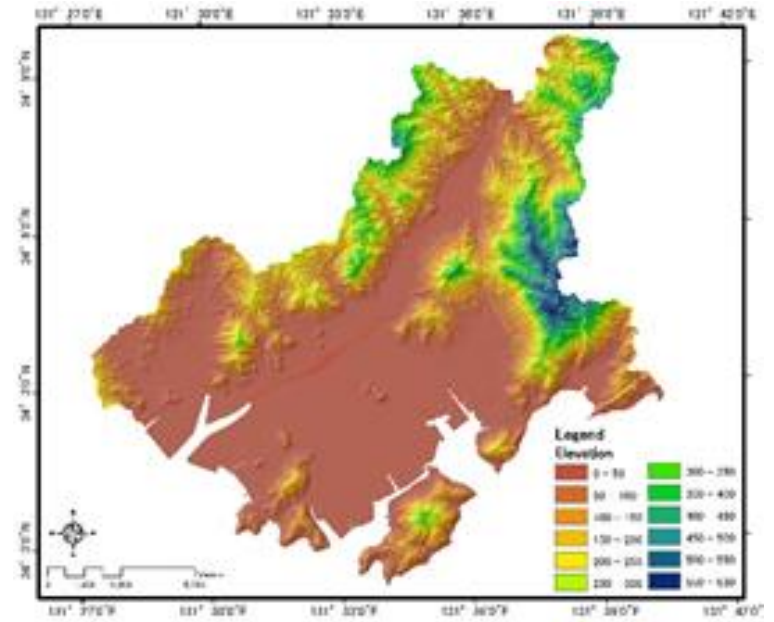

(a)

\begin{tabular}{|l|c|c|c|}
\hline CLASS & $\mathbf{W}^{+}$ & $\mathbf{W}^{-}$ & CONTRAST \\
\hline $\mathbf{5 5 0 - 6 3 0}$ & 0.0000 & 0.0000 & 0.0000 \\
\hline $\mathbf{5 0 0 - 5 5 0}$ & -2.6110 & 0.0137 & -2.6247 \\
\hline $\mathbf{4 5 0 - 5 0 0}$ & -3.1688 & 0.0249 & -3.1937 \\
\hline $\mathbf{4 0 0 - 4 5 0}$ & -2.9889 & 0.0416 & -3.0305 \\
\hline $\mathbf{3 5 0 - 4 0 0}$ & -0.7235 & 0.0361 & -0.7596 \\
\hline $\mathbf{3 0 0 - 3 5 0}$ & 0.2454 & -0.0324 & 0.2778 \\
\hline $\mathbf{2 5 0}-\mathbf{3 0 0}$ & 0.6665 & -0.1873 & 0.8538 \\
\hline $\mathbf{2 0 0 - 2 5 0}$ & 0.8239 & -0.4317 & 1.2556 \\
\hline $\mathbf{1 5 0 - 2 0 0}$ & 0.9054 & -0.9251 & 1.8305 \\
\hline $100-150$ & 0.8308 & -1.7449 & 2.5757 \\
\hline $\mathbf{1 0 - 1 0 0}$ & 0.6633 & -4.5054 & 5.1688 \\
\hline $0-50$ & 0.0000 & 7.6021 & -7.6021 \\
\hline
\end{tabular}

(b)

Figure 3. Elevation map (a) and its weigtht (b)

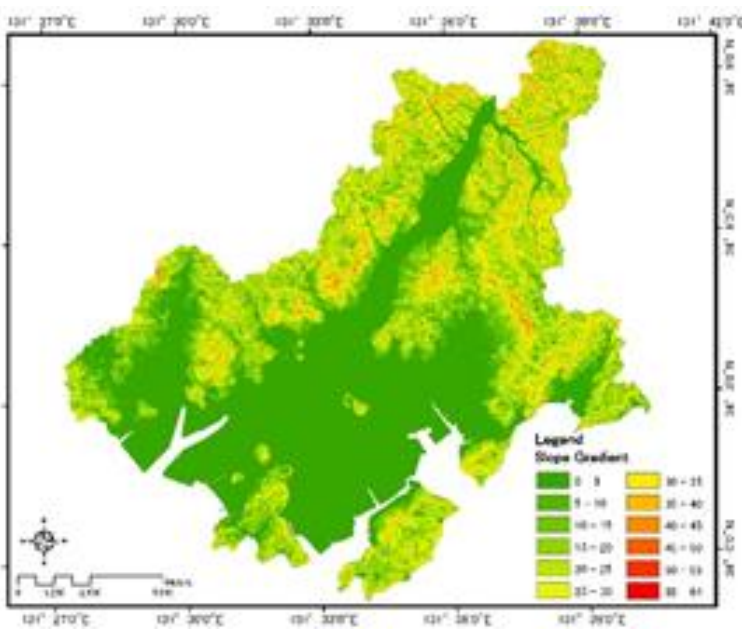

(a)

\begin{tabular}{|c|c|c|c|}
\hline CLASS & $W^{*}$ & W & CONTRAST \\
\hline $55-64$ & 0.0000 & 0.0000 & 0.0000 \\
\hline $50-65$ & 0.0000 & 0.0000 & 0.0000 \\
\hline $40-50$ & 0.5223 & -0.0013 & 0.5236 \\
\hline $40-45$ & 0.2770 & -0.0032 & 0.2801 \\
$35-40$ & 0.4889 & -0.0236 & 0.5125 \\
$30-35$ & 0.6277 & -0.0940 & 0.7218 \\
$25-30$ & 0.7953 & -0.3298 & 1.1251 \\
$20-25$ & 0.7964 & -0.7599 & 1.5564 \\
$15-20$ & 0.7612 & -1.6617 & 2.4229 \\
$10-15$ & 0.6508 & -2.9454 & 3.5963 \\
\hline-10 & 0.5342 & -4.8568 & 5.3910 \\
\hline $0-5$ & 0.0000 & 7.6021 & -7.6021 \\
\hline
\end{tabular}

(b)

Figure 4. Slope map (a) and its weigtht (b)

Elevation in the study area ranged from 0 to $630 \mathrm{~m}$ and the slope gradient ranged from $0^{\circ}$ to $64^{\circ}$. Based on the inventory map, landslides event occurred in the elevation range of 50 to $550 \mathrm{~m}$ and slope range of $5^{\circ}$ to $50^{\circ}$ with the highest frequency of occurrence at 200 $\mathrm{m}$ and $25^{\circ}$, this area was mostly known as forest. These classes were reclassified in $50-\mathrm{m}$ intervals and $5^{\circ}$ intervals and combined with the landslides evidence point from inventory map to calculate the weight. The remained parameters (aspect, land cover, and lithology) were also calculated by the same procedure.

Based on the weight calculation, the range of elevation from $>50 \mathrm{~m}$ to $<350 \mathrm{~m}$ are favorable for the occurrence of landslide, while slope angle $>5^{\circ}$ to $<50^{\circ}$ are favorable for the occurrence of landslides. Shallow landslides depend also on the availability of soil and colluvium, and in areas with slope gradient $>35^{\circ}$ soil and colluvium become less abundant (Crozier and Glade, 2005; Wieczorek, 1996). Therefore, a very steep slope does not always have the highest susceptibility. Slope direction of north, northeast and 
northwest were favorable for the occurrence of landslides. Agricultural field, settlement, bare soil, and forest were land covers that favorable for the occurrence of landslides. In particular, in the vegetation area that reduces root strength can carry a greater landslide in the forested upland areas than in the lowlands, even for the same slope gradients and lithology properties. In lithology parameter, granite, fan deposits, and middle terrace were favorable for the occurrence of landslides.

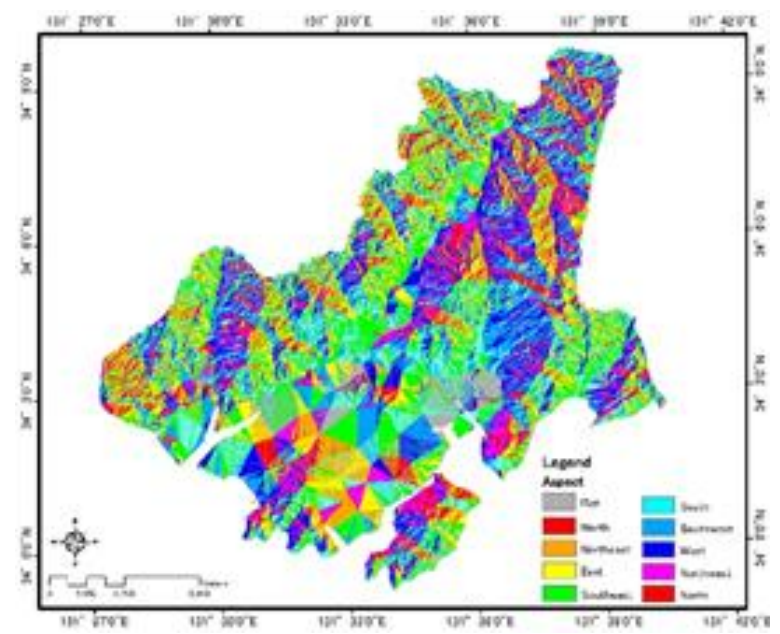

(a)

\begin{tabular}{|l|l|l|l|}
\hline CLASS & WPLUS & WMINUS & CONTRAST \\
\hline North W. & -0.0351 & 0.0050 & -0.0401 \\
\hline West & -0.1192 & 0.0368 & -0.1560 \\
\hline S. West & -0.1715 & 0.1016 & -0.2731 \\
\hline South & -0.1085 & 0.1212 & -0.2297 \\
\hline South E. & -0.1037 & 0.2277 & -0.3314 \\
\hline East & -0.0246 & 0.1167 & -0.1413 \\
\hline N. East & 0.0149 & -0.2350 & 0.2499 \\
\hline North & 0.0299 & -7.9134 & 7.9433 \\
\hline Flat & 0.0000 & 7.6021 & -7.6021 \\
\hline
\end{tabular}

(b)

Figure 5. Aspect map (a) and its weigtht (b)

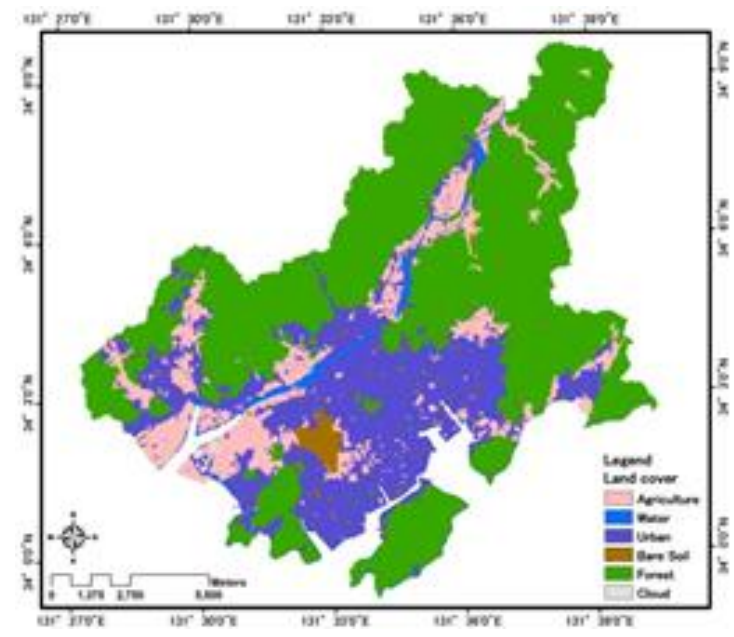

(a)

\begin{tabular}{|l|c|c|c|}
\hline CLASS & W $^{+}$ & W $^{-}$ & CONTRAST \\
\hline Cloud & 0.0000 & 0.0000 & 0.0000 \\
\hline Forest & 0.7619 & -4.2649 & 5.0268 \\
Bare soil & 0.7249 & -4.3850 & 5.1099 \\
Urban & 0.3601 & -4.9488 & 5.3089 \\
\hline Agriculture & 0.1069 & -3.8698 & 3.9767 \\
\hline Water & 0.0000 & 7.8166 & -7.8167 \\
\hline
\end{tabular}

(b)

Figure 6. Land cover map (a) and its weigtht (b)

The parameters weights, the parameters raster (evidence raster), and landslides point were combined to estimate the landslide susceptibility by using Logistic Regression in Arc-SDM tool. The susceptibility value in Hofu city ranged from 0 to 0.00895 . Figure 8 (a) shows landslide susceptibility map overlayed with landslide evidence points. LR results showed that $98 \%$ of the result calculations similar to the historical data of landslide event which is among 911 landslide points, 899 points were existed in high and very high susceptibility areas. The highest susceptibility area is shown by the scatter yellow colour with susceptibility value of 0.00895 , followed by red colour, purple, green, and the lowest susceptibility area is shown by brown colour with susceptibility value of 0 .

The result of LR coefficients (Fig 8 (b)) shows the indication of lithology as the most influencing parameter in this shallow landslides event by gaining a positive value. It is widely recognized that geological parameters greatly influence the occurrence of 
landslides, because lithological and structural variations often lead to a difference in strength and permeability of rocks and soils (Pradhan and Lee 2010). Among determinant factors (such as slope angle, slope aspect, and land cover), lithology with respect to type, physical and chemical characteristics and mineralogy play a significant role. Lithological condition most frequently considered in some literatures (Rodriguez-Otriz et al.1978; Hansen 1984; Guzzetti et al.1996, 1999; Ayalew et al., 2004).

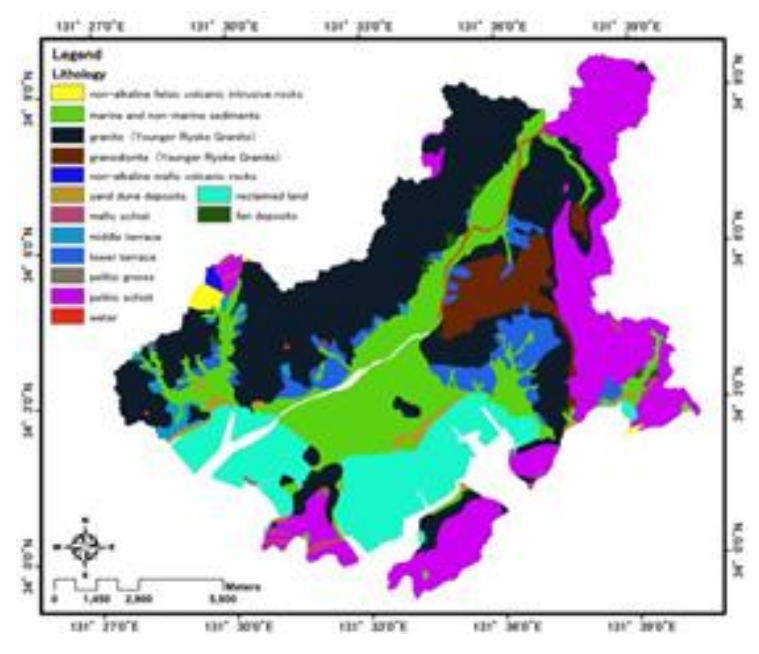

(a)

\begin{tabular}{|c|c|c|c|}
\hline CLASS & WPLUS & WMiNus & CONTRAST \\
\hline Peliticgn & 0.0000 & 0.0000 & 0.0000 \\
\hline $\begin{array}{l}\text { Non-ase } \\
\text { mafic }\end{array}$ & 0.0000 & 0.0000 & 0.0000 \\
\hline Granodiorite & 0.4753 & -0.0346 & 0.5099 \\
\hline Middle terr & 0.3108 & -0.0246 & 0.3354 \\
\hline $\begin{array}{l}\text { Fan } \\
\text { deposits }\end{array}$ & 0.2694 & -0.0220 & 0.2914 \\
\hline Reclaimed & -0.8276 & 0.1314 & -0.9590 \\
\hline sand dune & -0.8791 & 0.1447 & -1.0238 \\
\hline Masec schist & -0.9131 & 0.1540 & -1.0671 \\
\hline Low terr & -1.0856 & 0.2203 & -1.3059 \\
\hline $\begin{array}{l}\text { Non-as } \\
\text { telesele }\end{array}$ & -1.0584 & 0.2227 & -1.2811 \\
\hline Peatic schiat & -1.5159 & 0.5358 & -2.0517 \\
\hline Water & -1.5253 & 0.5444 & -2.0697 \\
\hline Marine & -1.8333 & 0.9687 & -2.8020 \\
\hline Granite & 0.0000 & 7.5975 & -7.5975 \\
\hline
\end{tabular}

(b)

Figure 7. Lithology map (a) and its weigtht (b)

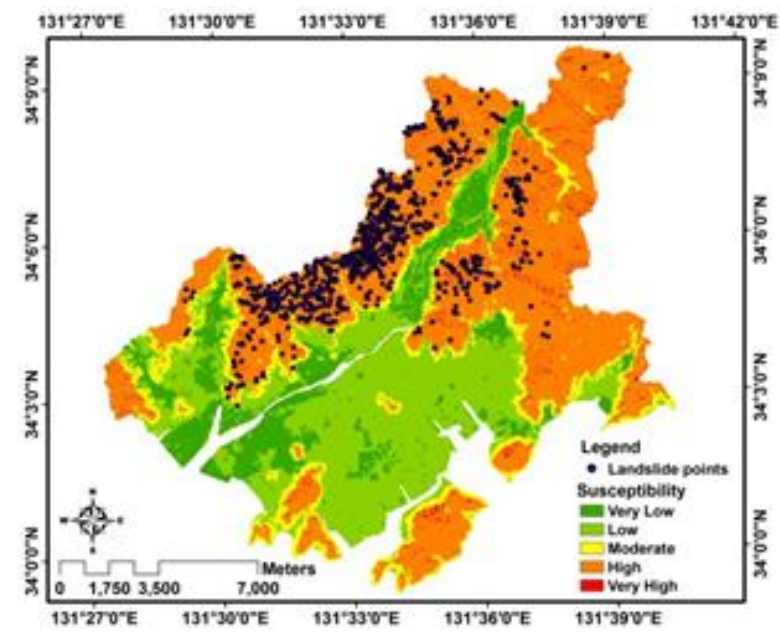

(a)

\begin{tabular}{|l|l|}
\hline Parameter & \multicolumn{1}{|c|}{ Coefficient } \\
\hline Constant & -4.8630 \\
Value & \\
\hline Elevation & -3.9264 \\
\hline Aspect & -0.1820 \\
\hline Slope & -1.9248 \\
\hline Geology & 0.21171 \\
\hline Land Cover & -2.0987 \\
\hline
\end{tabular}

(b)

Figure 8. Landslide susceptibility map (a) and parameter coefficient (b)

\section{Conclusions}

This study utilized remote sensing data and Geographic Information System (GIS) to study the relationship between parameters that initiates the landslide occurrence and generate landslide susceptibility map based on logistic regression model. Remote sensing data are considered as an effective way in providing data in dangerous areas. GIS is used as a spatial analysis tool to analyzed and calculate the parameter weights, estimated from the landslide evidence distribution, expressed the relation between the parameters and susceptibility to the occurrence of landslides. The weight calculation result revealed that elevation from $>50$ to $<350 \mathrm{~m}$ and slope angle from $>5^{\circ}$ to $<50^{\circ}$ are favorable for landslide occurrence. Slope direction of north and northeast were favorable for the occurrence of landslides. Agricultural field, settlement, bare soil, and forest were land covers that were favorable for the occurrence of landslides. In lithology parameter, 
graniodorite, fan deposits, and middle terrace were favorable for the occurrence of landslides.

To generate landslide susceptibility map, logistic regression (LR) model was used. The LR susceptibility value calculated from each parameters weight and raster combined with landslide evidence point, resulting values ranged from 0 to 0.00895 . The 0 value means there is no possibility for landslide to occur in these areas while 0.00895 means these areas has a high possibility for landslide to occur. LR results showed that $98 \%$ of the result calculations similar to the historical data of landslide event which is among 911 landslide points, 899 points were existed in high and very high susceptibility areas.

\section{References}

Agterberg, F. P., Bonham-Carter, G. F., Cheng, Q. M., \& Wright, D. F. (1993). Weights of evidence modeling and weighted logistic regression for mineral potential mapping. Computers in geology, 25, 13-32.

Ayalew, L., Yamagishi, H., Marui, H., \& Kanno, T. (2005). Landslides in Sado Island of Japan: Part II GIS-based susceptibility mapping with comparisons of results from two methods and verifications. Engineering Geology, 81(4), 432-445.

Ayalew, L., Yamagishi, H., \& Ugawa, N. (2004). Landslide susceptibility mapping using GIS-based weighted linear combination, the case in Tsugawa area of Agano River, Niigata Prefecture, Japan. Landslides, 1(1), 73-81.

Bonham-Carter, G. E., \& Cox, S. J. D. (1995). Geographic information systems for geoscientists: Modelling with GIS. Economic Geology and the Bulletin of the Society of Economic Geologists, 90(5), 1352-1353.

Bouvet, M., Goryl, P., Chander, G., Santer, R., \& Saunier, S. (2007). Preliminary radiometric calibration assessment of ALOS AVNIR-2. In IEEE International Geoscience and Remote Sensing Symposium 2007 (IGARSS 2007). Barcelona, Spain.

Chow, V. T., Maidment, D. R., \& Mays, L. W. (1988). Applied hydrology (McGraw-Hill series in water resources and environmental engineering). Singapore: McGraw-Hill Book Company.

Crozier, M. J., \& Glade, T. (2005). Landslide hazard and risk: issues, concepts and approach. In Glade, T., Anderson, M., Crozier M. (eds.), Landslide hazard and risk. Chichister: John Wiley and Sons, pp. 621-642.

Dai, F. C., \& Lee, C. F. (2002). Landslide characteristics and slope instability modeling using GIS, Lantau Island, Hong Kong. Geomorphology, 42(3), 213-228.

Guzzetti, F., Cardinali, M., \& Reichenbach, P. (1996). The influence of structural setting and lithology on landslide type and pattern. Environmental \& Engineering Geoscience, 2(4), 531-555.

Hansen, A. (1994). Landslide hazard analysis. In Brunsden, D. and D.D.B.. Prior (eds.), Slope Instability. New York, USA: Wiley \& Sons, pp. 523-602.

Pradhan, B., Lee, S., \& Buchroithner, M. F. (2010). Remote sensing and GIS-based landslide susceptibility analysis and its cross-validation in three test areas using a frequency ratio model. Photogrammetrie-Fernerkundung-Geoinformation, 2010(1), 17-32.

Robinson, G. R., \& Larkins, P. M. (2007). Probabilistic prediction models for aggregate quarry siting. Natural Resources Research, 16(2), 135-146.

Rodríguez-Ortiz, J. M., Prieto, C., \& Hinojosa, J. A. (1978). Regional studies on mass movements in Spain. In Proceedings of the 3rd IAEG Congress. Madrid, Spain.

Sah, A. K., Sah, B. P., Honji, K., Kubo, N., \& Senthil, S. (2012). Semi-automated cloud/shadow removal and land cover change detection using satellite imagery. In International Archives of the Photogrammetry, Remote Sensing and Spatial Information Sciences. Melbourne, Australia.

The Japan Landslide Society. (1994). Landslides in Japan. National Conference of Landslide Control [online]. Available at: http://www.tuat.ac.jp/ sabo/lj/index.htm

Wieczorek, G.F., 1996, Landslide triggering mechanisms. In Turner, A.K., \& Schuster, R.L. (Eds.), Landslides, investigation and mitigation: Special Report 247. Washington, D.C.: Transportation Research Board, National Academy Press, pp. 76-90.

(C) 201x by the authors; licensee Udayana University, Indonesia. This article is an open access article distributed under the terms and conditions of the Creative Commons Attribution (CC-BY) license (http://creativecommons.org/licenses/by/4.0/). 